\title{
DEGRADATION OF OIL DURING FRYING AND ITS EFFECT ON BIODIESEL PRODUCTION
}

\author{
Ayoola Ayodeji $\mathrm{A}^{\mathbf{1}^{*}}$, Adeeyo Opeyemi $\mathrm{A}^{\mathbf{2}}$, Efeovbokhan Vincent $\mathrm{E}^{\mathbf{3}}$, Mosugu Amadosi $\mathrm{T}^{\mathbf{4}}$ \\ ${ }^{1,2,3,4}$ Chemical Engineering, Covenant University, Ota, Nigeria \\ "Corresponding Author: ayodeji.ayoola@covenantuniversity.edu.ng
}

\begin{abstract}
The effects of frying unripe plantain and sweet potato (separately) in soyabean oil on the properties of the oil were investigated. Also, the effect of the degradation of the oil on biodiesel yield obtained from the oil was considered. Physico-chemical properties of soyabean oil (acid value, saponification value, viscosity, density, colour) were measured daily after being used for frying for days. The fatty acid profile of the oil was analysed daily using GC/MS and biodiesel was produced daily from the oil sample. The results of the frying process showed increase in oil Acid values in the two cases; sweet potato $(1.10-1.16 \mathrm{mgKOH} / \mathrm{g})$ and unripe plantain $(1.12-1.71 \mathrm{mgKOH} / \mathrm{g})$. And increase in oil saponification values $(146-271 \mathrm{mg} \mathrm{KOH} / \mathrm{g}$ for sweet potato and $175-$ $340 \mathrm{mgKOH} / \mathrm{g}$ for unripe plantain). The oil became less dense, less viscous and darker in colour for both batches during repeated frying. Five day Frying process reduced the percentage unsaturated fatty acid contents of oil (for unripe plantain from $81.94 \%$ to $36.80 \%$ and for sweet potato from $82.46 \%$ to $40.10 \%$ ) and increased the percentage saturated fatty acid composition of the oil (unripe plantain from $12.18 \%$ to $34.70 \%$ and sweet potato from $12.24 \%$ to $27.50 \%$ ). As frying progress, there was reduction in biodiesel yield, though insignificant difference in yield was observed between the biodiesel obtained from unripe plantain frying process and that obtained from the sweet potato frying process.
\end{abstract}

Keywords: Biodiesel, Soyabean Oil, Sweet Potato, Trans-Esterification, Unripe Plantain

\section{INTRODUCTION}

The practical notion of transforming vegetable oils or animal fats into renewable diesel fuel is an enthralling one and becomes the more interesting when even used cooking oils are still suitable for biodiesel production [1]. This is because the conversion of the used cooking oil to biodiesel (a sustainable energy source) would not only alleviate the world economy challenge on energy generation but also reduce the pollution problem encountered through the wrong disposal of the used cooking oil [1], [2], [3].

Biodiesel, renewable energy, is obtained from a reaction between the triglycerides of plant oils (or animal fats) and alcohol through trans-esterification process, in the presence of a catalyst [3], [4], [5], [6]. Triglycerides (esters of fatty acids with glycerol) naturally possess several different fatty acids which can be attached to one glycerol backbone. The different fatty acids contained in the triglycerides makeup the fatty acid profile or composition of the vegetable oil or animal fat. Fatty acid composition is the one of the important factors influencing the characteristics of vegetable oil and animal fat [7], [8], [9].

Soyabean oil in comparison with other major vegetable oils contains a high percentage composition of unsaturated fatty acid content (mostly linoleic and oleic acids) and a low content of saturated fatty acid content, majorly palmitic acid [9], [10]. As a result of the high concentration of unsaturated fatty acid in soya oil, most triglyceride molecules contain at least two unsaturated fatty acids [11], [12], [13].
The degradation of soyabean oil refers to chemical breakdown changes in the structure of the oil due to applied heat at high temperature. Frying is a process of immersing food materials (such potato, plantain, meat) in hot oil a period of time as deemed fit for the food material to undergo physical changes [14], [15], [16], [17].

During frying process, the oil interacts with the food materials [18]. Hydrolysis, oxidation, and polymerisation of oil are the common chemical reactions that take place during frying in oil. These reactions generate volatile and nonvolatile compounds; most of the volatile compounds evaporate in to the atmosphere with steam while the nonvolatile compounds react with or are absorbed by fried foods [15], [18].

These reactions resulted into change in both the physical and chemical properties of the oil and fried foods [14], [19], [20]. Unsaturated fatty acids of the oil have been found to decrease with increased frying duration. Also change occurred in the oil physical parameters like density, viscosity, foaming, colour. Frying temperature and frying time, kind of frying oil and nature of the materials to fry are responsible for the degradation of the frying oil which undergoes hydrolysis, oxidation and polymerization during frying [14], [21], [22].

The focus of this research work is to study the change in the physical and chemical properties of soyabean oil used for frying unripe plantain and sweet potato; and to consider how the degradation of soyabean oil (through frying) will affect the yield of biodiesel obtained from the oil through transesterification process. 


\section{MATERIALS AND METHODS}

2.1 Frying: 3L of soyabean oil was purchased from Justrite supermarket Ota, Nigeria. Sweet potato and unripe plantain (obtained from a local market in Ota) were peeled and cut into uniform pieces. Each batch of the two food materials was fried separately for a period of 15 minutes (3 times daily) for 5 days, amounting to 45 minutes of frying time per day for each food material. At the commencement of the frying process, $1.5 \mathrm{~L}$ of the virgin soyabean oil was used for each of the two materials, $100 \mathrm{~g}$ of the food materials was used during each of the frying process and the frying temperature was maintained at $150^{\circ} \mathrm{C}$ throughout the frying time.

2.2 Biodiesel Production: Biodiesel was produced from the reaction between soyabean oil and methanol through transesterification process. After each day frying process, the oil used was free of impurities and $100 \mathrm{~g}$ of the oil was used for each batch of transesterification process. Required amount of methanol was weighed and $1.5 \mathrm{~g}$ of $\mathrm{KOH}$ was added and stirred well until $\mathrm{KOH}$ dissolved completely. The mixture of methanol and $\mathrm{KOH}$ (potassium methoxide solution) was then added to the heated oil. Transesterification reaction was allowed to take place at the methanol/oil mole ratio of $6,60^{\circ} \mathrm{C}$ reaction temperature, $\mathrm{KOH}$ catalyst concentration of $1.5 \mathrm{w} / \mathrm{w}$ oil and reaction time of 60 minutes. The two products formed were transferred to the separating funnel (top layer biodiesel and bottom layer of glycerol) and then separated. The glycerol was first drained out of the separating funnel, biodiesel was then washed with warm water. The wet biodiesel obtained was heated at $110^{\circ} \mathrm{C}$ for 12 minutes to remove water present.

\section{RESULTS AND DISCUSSION}

The results of the fatty acid composition analysis (using Agilent Technology 7890A GC/MS) is shown in Table 1. Fatty acid composition of soyabean oil shows linoleic fatty acid forming a major constituent of fatty acids present. Percentage of unsaturated fatty acids is $83.01 \%$ while saturated fatty acids constituted $13.32 \%$. Unsaturated fatty acids are more susceptible to hydrolysis and oxidation reactions than saturated fatty acids due to weaker carbon bonding in unsaturated carbons [19], [23], [24].

Table 1: Fatty acid composition of virgin soyabean oil.

\begin{tabular}{cccc}
\hline No & $\begin{array}{c}\% \\
\text { composition }\end{array}$ & Name & $\begin{array}{c}\text { Symbol } \\
\text { (No of double } \\
\text { bond) }\end{array}$ \\
\hline 1 & 56.1 & Linoleic & C18:2 \\
2 & 17.96 & Oleic & C18:1 \\
3 & 1.51 & Stearic & C18:0 \\
4 & 2.02 & Palmitoleic & C16:1 \\
5 & 11.81 & Palmitic & $\mathrm{C} 16: 0$ \\
6 & 6.93 & Linolenic & $\mathrm{C} 18: 3$ \\
\hline
\end{tabular}

(13.32\% Saturated Fatty Acids, 83.01\% Unsaturated Fatty Acids)

Table 2: Fatty Acid Composition of Soyabean Oil After Daliy Frying

\begin{tabular}{|c|c|c|c|c|c|c|c|c|c|c|c|}
\hline \multirow[t]{3}{*}{ Fatty Acid } & \multirow[t]{3}{*}{ Symbol } & \multicolumn{10}{|c|}{$\%$ Composition } \\
\hline & & \multicolumn{5}{|c|}{ Unripe Plantain } & \multicolumn{5}{|c|}{ Sweet Potato } \\
\hline & & $1^{\text {st }}$ & $2^{\text {nd }}$ & $3^{\text {rd }}$ & $4^{\text {th }}$ & $5^{\text {th }}$ & $1^{\text {st }}$ & $2^{\text {nd }}$ & $3^{\text {rd }}$ & $4^{\text {th }}$ & $5^{\text {th }}$ \\
\hline Palmitoleic & C16:1 & 1.20 & 0.91 & 0.88 & 0.64 & 0.59 & 1.02 & 0.86 & 0.79 & 0.65 & 0.60 \\
\hline Linoleic & C18:2 & 13.61 & 8.79 & 7.42 & 2.30 & 1.09 & 13.88 & 10.37 & 8.66 & 4.67 & 2.76 \\
\hline Oleic & C18:1 & 50.38 & 44.75 & 38.45 & 32.53 & 30.07 & 53.22 & 45.40 & 41.21 & 31.81 & 28.72 \\
\hline Linolenic & C18:3 & - & - & - & - & - & - & - & - & - & - \\
\hline Petroselinic & C18:1 & 16.75 & 14.54 & 10.81 & 6.73 & 6.05 & 16.34 & 14.03 & 11.09 & 10.95 & 8.02 \\
\hline Palmitic & C16:0 & 10.63 & 14.16 & 20.18 & 24.67 & 30.29 & 10.71 & 14.87 & 20.71 & 21.97 & 23.34 \\
\hline Capric & C10:0 & - & - & - & - & 0.56 & - & - & - & - & - \\
\hline Stearic & C18:0 & 1.55 & 1.86 & 2.94 & 3.22 & 3.85 & 1.53 & 2.91 & 2.72 & 2.53 & 3.06 \\
\hline Tridecanoic & C13:0 & - & - & - & - & - & - & - & - & - & 0.43 \\
\hline Pentadecanoic & C15:0 & - & - & - & - & - & - & - & - & - & 0.67 \\
\hline \multirow{2}{*}{$\begin{array}{l}\text { \% Saturated } \\
\% \text { Unsaturated }\end{array}$} & & 12.18 & 16.02 & 23.12 & 27.89 & 34.70 & 12.24 & 17.78 & 23.43 & 24.50 & 27.50 \\
\hline & & 81.94 & 68.99 & 57.56 & 42.20 & 36.80 & 82.46 & 70.66 & 61.75 & 48.08 & 40.10 \\
\hline
\end{tabular}

Table 2 shows the analysis of the distribution of fatty acids compositions in soyabean oil after daily frying process, using GC/MS. The reduction in percentage composition of fatty acid observed may likely due to the degradation of the oil (hydrolysis) during frying process. 


\subsection{Acid Value:}

Figure 1 shows that the acid value of the soyabean oil increases with increase in number of frying time of both the sweet potato and unripe plantain. This implies that the free fatty acids (FFA) present in the oil after frying increased with frying, as reported by [20]. Also, the acid value of the oil used for frying unripe plantain was higher than the value obtained from the oil used during the frying of sweet potato, under the same condition. This could be due to higher moisture content in unripe plantain. The higher the moisture contents in food materials the higher the hydrolysis of the frying oil. Moisture in foods induces and accelerates oxidation with hydrolytic compounds and water released into the oil during frying causes degradation of oil, thereby increase the release of FFA [3], [22].It is important to note that the acid values obtained after the fifth day is still within the tolerable level for biodiesel production [2].

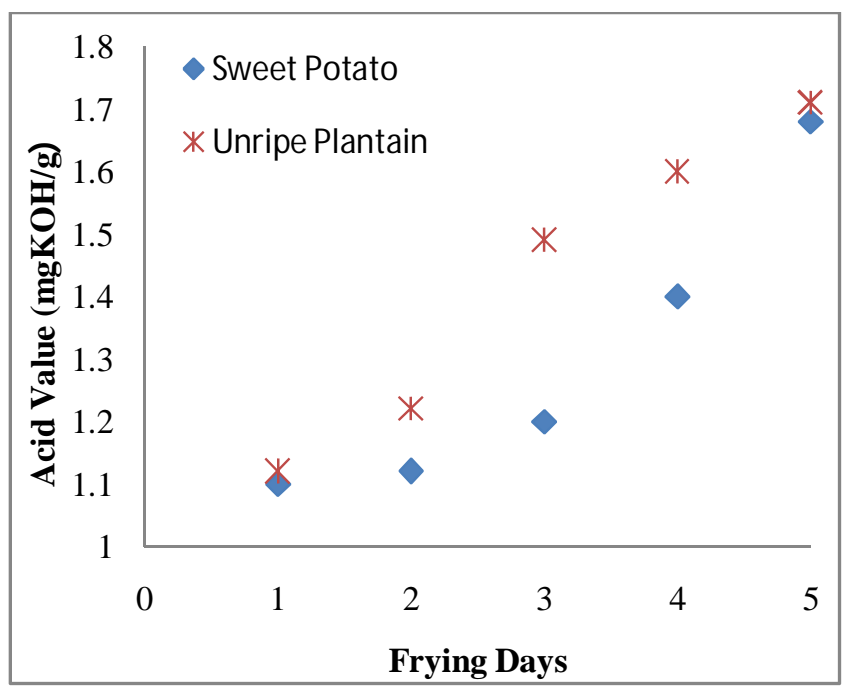

Figure 1: Acid Value of Soyabean Oil After Daily Frying

\subsection{Saponification value}

Figure 2 shows the saponification valuesof soyabean oil obtained after daily frying. Soyabean oil used for frying unripe plantain has greater sponification value compared to value obtained when soyabean oil was used for frying, under the same experimental conditions. This indicates that the continuously applied heat caused triglyceride breakage (through hydrolysis reaction) and increase the free fatty acids in the oil; resulting into decrease in both the unsaturated fatty acids composition and molecular weight of the oil (Table 1). It was also observed that the heat applied resulted into gradual increase in the percentage saturated fatty acids of the oil. The higher saponification value of soyabean oil used for frying unripe plantain could be accounted for by the higher moisture content in the unripe plantain.

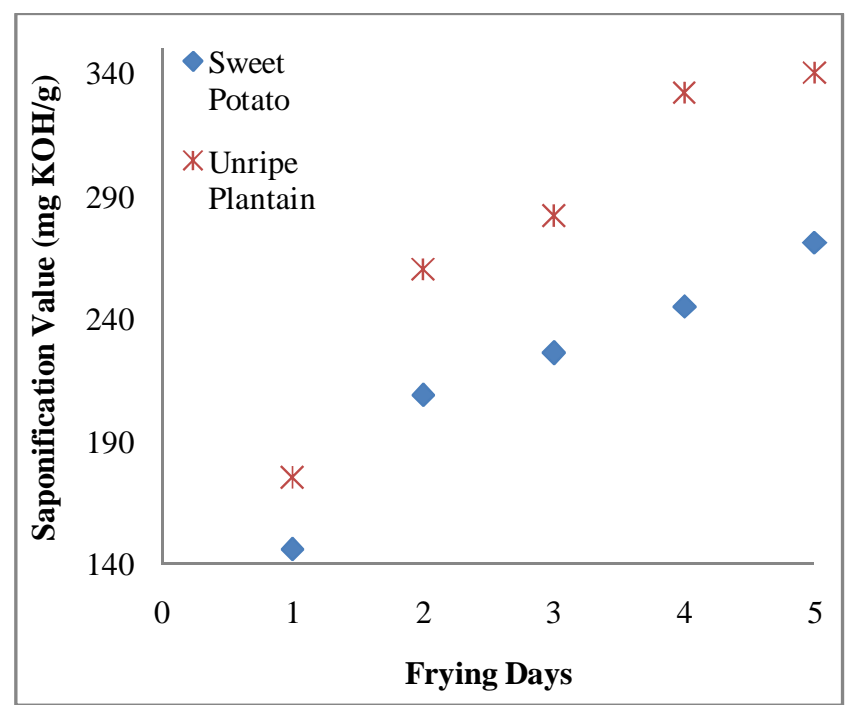

Figure 2: Sap. Value of Soyabean Oil After Daily Frying

\subsection{Density:}

In Figure 3, reduction in oil density recorded with time was due to the fact that the oil became lighter as heating progressed. Comparatively, the difference in density between the oil used for frying unripe plantain and that of the one used for frying sweet potato was insignificant. The oil density range recorded (in the two processes) falls within the density value specification for biodiesel production [2].

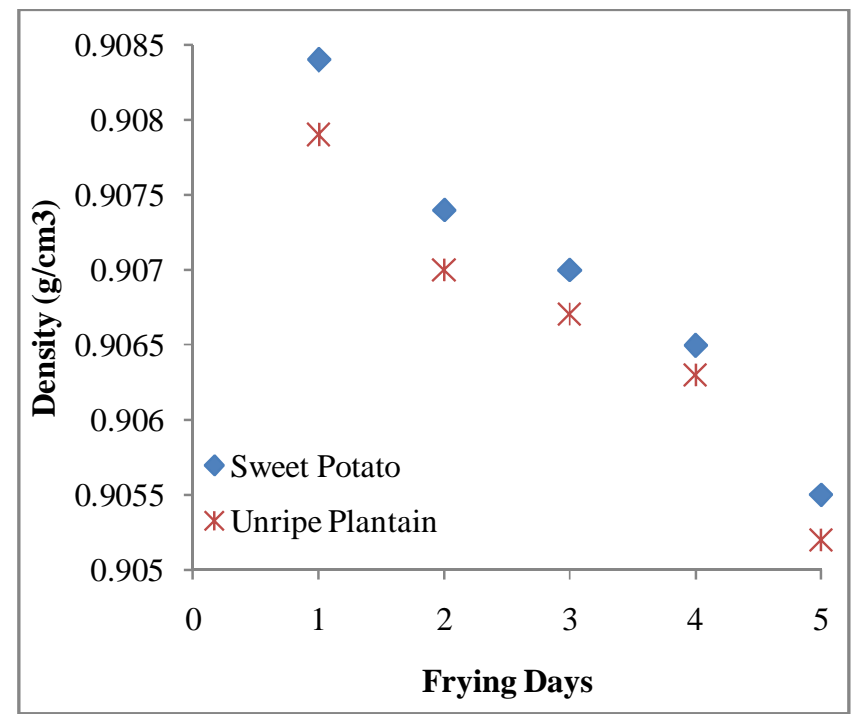

Figure 3: Density of Soyabean Oil After Daily Frying 


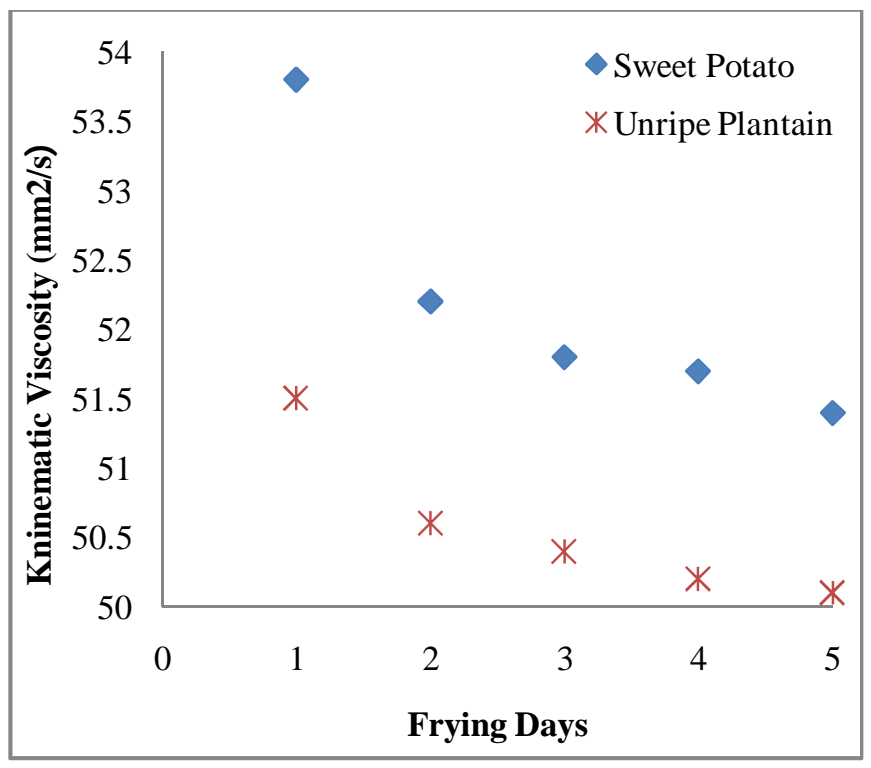

Figure 4: Viscosity of Soyabean Oil After Daily Frying

\subsection{Viscosity:}

Figure 4 shows the viscosity of the soyabean oil reduces as frying process progresses. The decrease in viscosity may likely due to the breaking of the bonds of oil triglycerides through heating. The viscosity of soyabean oil used for frying sweet potato was higher than that obtained fromsoyabean used for frying unripe plantain (under same condition). This could indicate that sweet potato contains more constituents that induce or promote polymerization reactions, leading to formation of more polymer compounds [11].

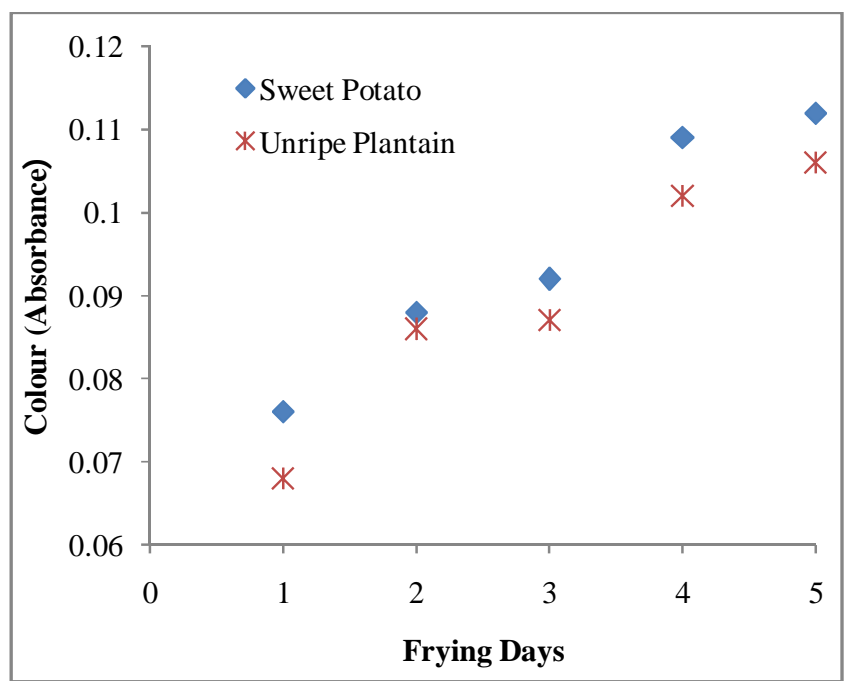

Figure 5: Colour of Soyabean Oil After Daily Frying

\subsection{Colour:}

Color is an important physical property of oil used to determine quality or level of degradation. It is a function of the substance's ability to absorb and to emit light. The absorbance of the colour of the soyabean oil was measured using a UV - VIS Spectrophotometer. As absorbance values tend towards zero, the oil becomes clearer, lighter or colourless. As the value tends towards 1, the oil substance becomes darker or opaque. Figure 5 shows that the absorbance values of the oil became darker or more opaque as frying progress. Darkening of the oil during deep-fat frying is due to the polymer formation of carbonyl compounds and non-polar compounds of foodstuff solubilized in the oil [25]. The values obtained in the graph indicated that the oil used for frying sweet potato oil batch is darker than unripe plantain oil, and this agrees with the viscosity trend that polymer compounds form during the frying of sweet potato are more than that obtained during the frying of unripe plantain.

\subsection{Biodiesel Yield:}

A downward trend was observed in biodiesel yield obtained from soyabean oil used for frying (Figure 6). The heating process allowed the fatty acids of the oiltriglycerides to undergo hydrolysis, oxidation or polymerization reactions to form new compounds. These reactions reduced the number of fatty acid present in the oil, increased the percentage of polymer compounds and other by-products formed. Hence, a reduction in fattyacids of the oil triglycerides that undergone trans-esterification reaction with methanol resulted into low biodiesel yield, as frying progress [26].

The difference in biodiesel yieldobtained (on daily basis) from the oil used for frying unripe plantain and the oil used for frying sweet potato was insignificant (with the exception of the $5^{\text {th }}$ day).

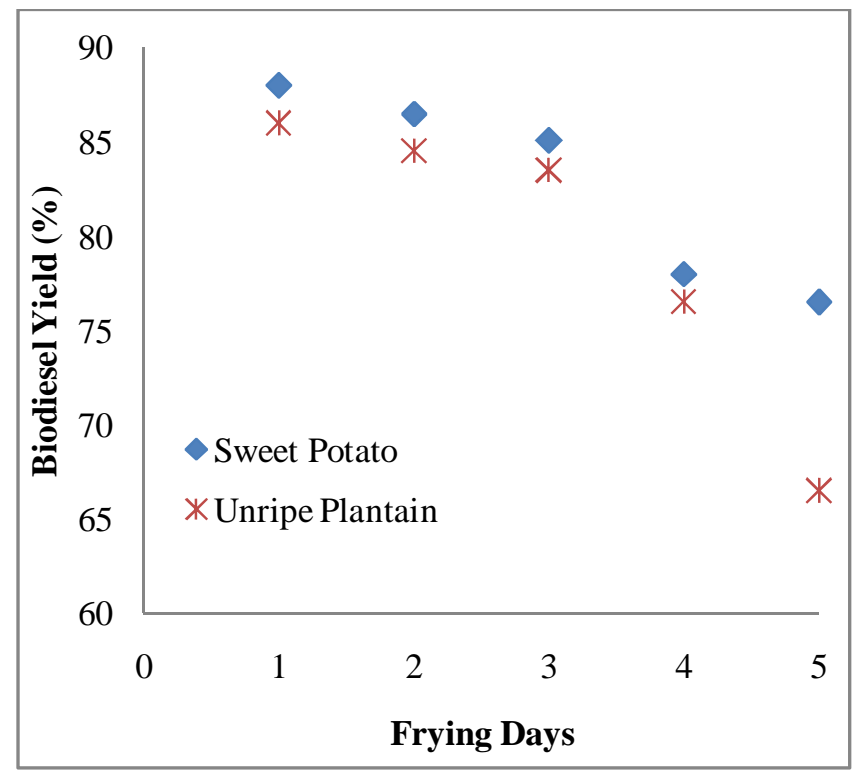

Figure 6: Biodiesel Yield Obtained After Daily Frying

The composition of fatty acids in soyabean oil after daily frying showed a downward trend in unsaturated fatty acids and an upward trend in saturated fatty acids, as frying progress (Figure 7 and Table 2). This is because the heating of the oil caused some unsaturated $\mathrm{C}-\mathrm{C}$ bonds converted to saturated bonds. 


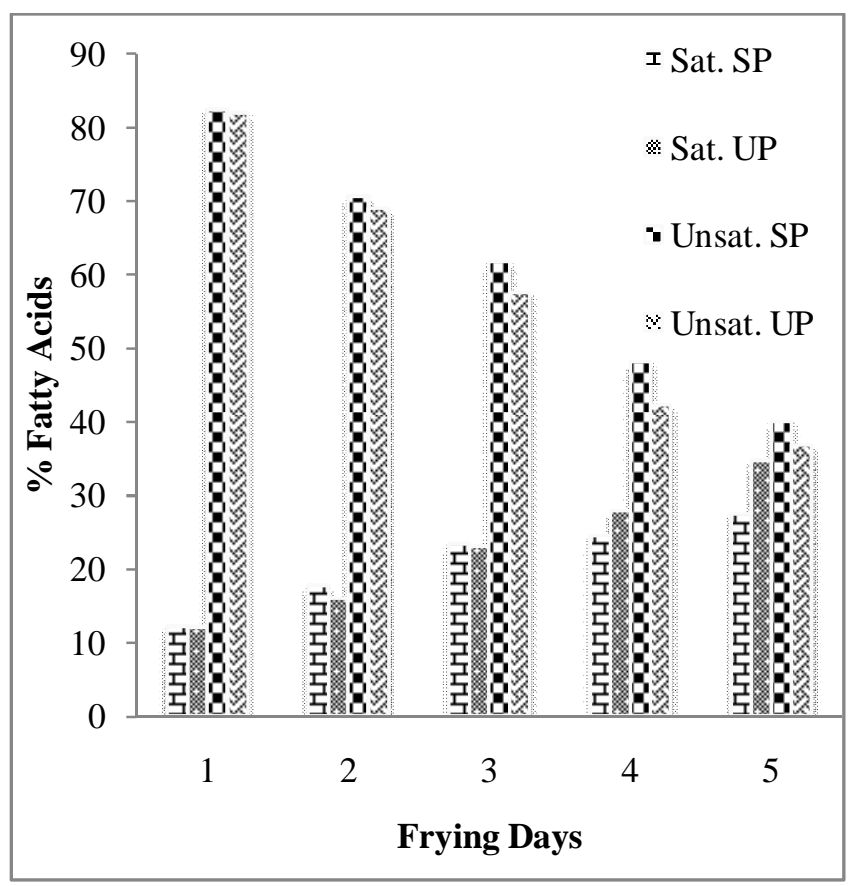

Figure 7: Fatty Acids Composition After Daily Frying

\section{CONCLUSION}

It was found that the percentage of the total fatty acid composition in soyabeanoil decreased as frying progressed, during the frying of both the unripe plantain and sweet potato (though there was increase in saturated fatty acids). Low biodiesel yields recorded as frying progressed was due to the degradation of fatty acids in oil through hydrolysis, oxidation or polymerisation processes. Lower biodiesel yield observed in the frying of potato suggested that the effects of the degradation were more pronounced during the frying of unripe plantain.

\section{REFERENCES}

[1] Kulkarni M. G., Dalai A. K. (2006). Waste Cooking Oil - An Economical Source for Biodiesel: A Review. Ind. Eng. Chem. Res., 45, 2901-2913.

[2] Ayoola A. A.(2015). Production and Life Cycle Assessment of Biodiesel Produced from Three Waste Oils. Ph.D. Thesis, Chemical Engineering Department, Covenant University, Nigeria.

[3] Canakci M., Gerpen J. V. (2001). Biodiesel Production from Oils And Fats With High Free Fatty Acid. Trans ASAE, 44(6), 1429-1436.

[4] Ayoola A. A, Hymore F. K., Obande M. A.,Udeh I. N. (2012). Optimization of Experimental Conditions for Biodiesel Production, International Journal of Engineering \& Technology, 12 (6), 130 - 134.

[5] Pinto A.C., Guarieiro L. N., Rezende M.J., Ribeiro N.M., Torres E.A., Lopes W.A., De Pereira, P.A., De Andrade, J.B. (2005). Biodiesel: An Overview. Journal of the Brazilian Chemical Society, 16(6), 1313-1330.

[6] Srivastava A., Prasad R. (2000). Triglycerides-based Diesel Fuels. Renew Sustain Energy Rev, 4, 111-33.

[7] Gerhard K. (2005). Dependence of Biodiesel Fuel Properties on the Structure of Fatty Acid
Alkyl Esters. Fuel Processing Technology, 86, 1059 1070.

[8] Kim I-H, Kim C-J, Kim D-H. (1999). Physicochemical Properties Of Methyl Linoleate Oxidized At Various Temperatures. Korean J Food SciTechnol, 31, 600-605.

[9] Sanchez-Muniz F. J., Cuesta C., Garrido-Polonio C. (1993). Sunflower Oil Used For Frying: Combination Of Column, Gas And High Performance Size Exclusion Chromatography For Its Evaluation. $J$ Am Oil Chem Soc., 70235- 240.

[10] Rojo J. A., Perkins E. G. (1987). Cyclic Fatty Acid Monomer Formation In Frying Fats. Determination And Structural Study. J AmOilChem Soc., 64, 414-21.

[11] Blumenthal M. M. (1991). A New Look At The Chemistry And Physics Of Deep Fat Frying. Food Technol. 45, 68- 71.

[12] Liu, K. (2000). Expanding Soybean Food Utilization. Food Technol, 54, 46-47.

[13] Naz S., Siddiqi R., Sheikh H., Sayeed S. A. (2005). Deterioration Of Olive, Corn And Soybean Oils Due To Air, Light, Heat And Deep Frying. Food Res Intl., 38, 127- 134.

[14] Choe E., Min D. B. (2007). Chemistry of Deep-Fat Frying Oils. Journal of Food Science, 72, 77 - 86

[15] Paul S., Mittal G. S. (1997). Regulating The Use Of Degraded Oil/Fat In Deep Fat/Oil Food Frying. Crit Rev Food SciNutr, 37, 635-662.

[16] Tseng Y-C, Moreira R. G, Sun X. (1996). Total Frying - Use Time Effects On Soybean Oil Deterioration And On Tortilla Chip Quality. Intl J Food Sci Technol. 31, 287- 294.

[17] Romero A., Cuesta C., Sanchez-Muniz F. J. (1998). Effect Of Oil Replenishment During Deep Fat Frying Of Frozen Foods In Sunflower Oil And High Oleic Acid Sunflower Oil. J AmOilChemSoc,75, 161- 167.

[18] Fedell E. (1998). Physical-Chemical Aspects of the Frying Process. (pp. 261-264). Milano-Italy: Grasas y Aceltes.

[19] Bastida S., Sanchez-Muniz F. J. (2001). Thermal Oxidation of Olive Oil, Sunflower Oil and A Mix of Both Oils During Forty Discontinuous Domestic Frying of Different Foods. Food SciTechnol, 7, 15-21.

[20] Chung J, L. (2004). Oxidative Stability of Soybean And Sesame Oil Mixture During Frying of Flour Dough. Journal of Food Science, 69, 574-578.

[21] Dana D, B. (2003). The Protective Role Of Water Injection On Oil Quality In Deep Fat Frying Conditions. Eur Food Res Technol., 104-109.

[22] Dobarganes C., Marquez-Ruiz G., Velasco J. (2000). Interactions BetweenFat And Food During Deep Frying. Eur J Lipid SciTechnol, 102, 521- 528.

[23] Takeoka G.R, Full G.H, Dao L.T. (1997). Effect of Heating On The Characteristics And Chemical Composition Of Selected Frying Oil And Fat. J Agric Food Chem, 45, 3244-3249.

[24] Tompkins C., Perkins E. G. (2000). Frying Performance of Low Linolenic Acid Soybean Oil. J Am Oil ChemSoc, 77, 223- 229.

[25] Gutierrez R., Gonzales-Quijano F., Dorbarganes M. C. (1988). An Analytical Procedures For The Evaluation 
of Used Frying Fats In Frying of Food. Principles, Changes, New Approaches. Eds. G. Varela, A. E. Bender, I. D. Morton, Ellis Harwood Ltd., Chichester (England).

[26] Leung, D.Y., Wu, X., Leung, M.K. (2010). A Review On Biodiesel Production Using Catalyzed Transesterification. Applied Energy, 87, 1083- 1095. 